TITLE:

\title{
Discrimination among host tree species by the ambrosia beetle Platypus quercivorus
}

\author{
$\operatorname{AUTHOR}(\mathrm{S}):$
}

Yamasaki, Michimasa; Futai, Kazuyoshi

\section{CITATION:}

Yamasaki, Michimasa ... [et al]. Discrimination among host tree species by the ambrosia beetle Platypus quercivorus. Journal of Forest Research 2012, 17(2): 149-155

ISSUE DATE:

2012-04

URL:

http://hdl.handle.net/2433/154895

\section{RIGHT:}

The final publication is available at www.springerlink.com; This is not the published version. Please cite only the published version.; この論文 は出版社版でありません。引用の際には出版社版をご確認ご利用くだ さい。 


\section{Title}

2 Discrimination among host tree species by the ambrosia beetle Platypus

3 quercivorus

4

$5 \quad$ Names and addresses of the authors

6 Michimasa Yamasaki $^{* 1}$ and Kazuyoshi Futai ${ }^{* 2}$

$7 \quad * 1$ : Laboratory of Forest Biology, Division of Forest and Biomaterials

8 Science, Graduate School of Agriculture, Kyoto University, Kyoto, Japan

9 *2: Laboratory of Environmental Mycoscience, Division of Environmental

10 Science and Technology, Graduate School of Agriculture, Kyoto University,

11 Kyoto, Japan

12

13 Address of the corresponding author (Michimasa Yamasaki)

14 Laboratory of Forest Biology, Division of Forest and Biomaterials Science,

15 Graduate School of Agriculture, Kyoto University, Kitashirakawa

16 Oiwake-cho, Sakyo-ku, Kyoto 606-8502, Japan

17 Tel: $+81-75-753-6479$

18 Fax: +81-75-753-6129

19 E-mail: risei@kais.kyoto-u.ac.jp

20

21 Article type, subject area and field

22 Original article, Biology and Ecology, Entomology

24 Page count

2529 pages

27 Number of tables and figures

281 table, 3 figures 
29 Abstract

The ambrosia beetle Platypus quercivorus is a vector for the fungus that

31 causes Japanese oak wilt, and susceptibility to infestation by $P$. quercivorus

32 varies by tree species. We postulated that $P$. quercivorus discriminates

33 among host tree species differing in susceptibility to attack. To test this

34 postulate, we counted the number of flying male beetles (NFM), the number

35 of holes bored by male beetles $(\mathrm{NH})$, and the number of flying female

36 beetles (NFF) per unit area of bark surface in three fagaceous tree species:

37 Quercus crispula (with high susceptibility to infestation) and Q. serrata and

38 Castanea crenata (both with low susceptibility). NFM and NH were used to

39 calculate the proportion of male beetles that bored holes out of those that

40 flew to the tree (PBM). We used generalized additive models to predict NFM,

41 NFF, and PBM. The locations of trees, expressed as $\mathrm{x}$ and $\mathrm{y}$ coordinates,

42 numbers of weeks after the first male beetle's flying (WEEK), diameters of

43 trees $130 \mathrm{~cm}$ above ground (DBH), and tree species (SP) were incorporated

44 into the models as candidate explanatory variables. The best-fit models for

$45 \quad$ NFM and NFF included WEEK and DBH and the effect of location; SP was

46 not included in the models. For PBM, the best-fit model included WEEK,

47 DBH, and SP. The results indicate that male P. quercivorus prefer $Q$.

48 crispula to $Q$. serrata and $C$. crenata and that selection is made before 
49 boring holes on trees, but that $P$. quercivorus do not discriminate among host 50 species when they fly to trees.

51

52 Keywords

53 Castanea crenata, Host selection, Japanese oak wilt, Quercus crispula, 54 Quercus serrata 
In general, ambrosia and bark beetles use weakened trees as hosts

(Wood 1982). Random flight and random landings on trees are thought to reduce beetle fitness in environments with low densities of weakened trees; accordingly, beetles select appropriate hosts through visual or olfactory cues (Byers et al. 2004; Zhang and Schlyter 2004; Pureswaran and Borden 2005; Campbell and Borden 2006). The beetles start to attack healthy trees en masse when they reach epidemic population sizes (Paine et al. 1997).

64 Subsequently, resource availability for the beetles increases dramatically, especially in forests that are dominated by suitable host tree species. Even during these epidemic phases, beetles need to select hosts carefully in forests with high diversities of tree species, many of which are unsuitable. In Japan, populations of ambrosia beetle Platypus quercivorus (Murayama) (Coleoptera: Platypodidae) are considered to have reached epidemic proportions in recent years. As vectors, their attacks on apparently

71 healthy-looking trees lead to Japanese oak wilt (Ito and Yamada 1998;

72 Kobayashi and Ueda 2005). Although they attack several species of

73 Fagaceae, beetle reproductive success varies by tree species (Kato et al.

74 2001; Kobayashi et al. 2004). In brief, forest tree species fall into three types 
75 for P. quercivorus: suitable Fagaceae, unsuitable Fagaceae, and non-host

76 tree species. In such an environment, we suggest that $P$. quercivorus

77 preferentially selects suitable Fagaceae trees using visual or olfactory cues.

78 Conversely, we postulate that tree species are avoided by $P$. quercivorus

79 when these trees are associated with a reduced level of beetle fitness. Lower P. quercivorus preference for particular tree species can be

81 identified by reduced beetle activity in several phases of the infestation

82 process. The infestation process of $P$. quercivorus can be divided into four

83 phases. In phase 1, male beetles fly to a tree; in phase 2, they bore shallow

84 holes in the bark; in phase 3 , female beetles fly to the tree; and in phase 4,

85 after mating, male and female beetles construct galleries in the sapwood for

86 reproduction (Soné et al. 1998; Esaki et al. 2004). Previous studies on beetle

87 host selection strongly suggest that $P$. quercivorus avoids unfavorable tree

88 species in the earlier phases of infestation (phases 1-3) (Urano 2000;

89 Yamasaki and Futai 2008). Exclusion of unfavorable trees before landing

90 has been suggested for bark beetles that use conifers as their hosts; they use

91 olfactory cues to distinguish non-host broad-leaved tree species from the

92 correct host tree species (Zhang 2003; Byers et al. 2004; Zhang and Schlyter

93 2004). Moreover, pre-landing exclusion of thinner trees and post-landing

94 exclusion of trees with infection histories (for which there are reduced 
probabilities of successful beetle reproduction) have been demonstrated in

96 field studies of P. quercivorus (Urano 2000; Yamasaki and Futai 2008).

When discerning differences in beetle activity among tree species, it is necessary to take into account other variables that affect behavior. Reported effects of host tree size on beetle activity (Akaishi et al. 2006; Yamasaki and Futai 2008) show that it is necessary to compare beetle activity on different

101 tree species within the same size class. However, this is difficult to achieve 102 in a field study. Assuming that there are

1031 linear relationships between tree size and beetle activity parameters

104 (BAPs); and

1052 normal distributions in BAPs,

106 analysis of covariance is appropriate for the detection of differences among

107 tree species. Even when the first assumption is satisfied, BAPs may not be

108 normally distributed. In addition, beetle activity fluctuates with time, and the

109 relationship between time and beetle activity is apparently nonlinear (Urano

110 2000; Ueda and Kobayashi 2001b). Moreover, beetle activity may show

111 dramatically high values at particular locations because of the effect of the

112 beetle's aggregation pheromone (Ueda and Kobayashi 2001a; Tokoro et al.

113 2007), and this effect must be taken into consideration. Accordingly, we

114 used a generalized additive model with nonlinear effects of time and location 
115 as alternative methods for investigating differences in beetle activities

116 among tree species.

117 Capture of wild $P$. quercivorus with chemical traps is considered an

118 effective method for protecting fagaceous trees. A kairomone is emitted

119 from trees and may affect host selection by $P$. quercivorus, but its chemical

120 nature is as yet unknown. However, the beetle's aggregation pheromone has

121 been identified (Kashiwagi et al. 2006). Unfortunately, a synthetic

122 pheromone failed to capture the beetle effectively (Kamata et al. 2008).

123 Determining differences in beetle activity among tree species will help to

124 clarify ecological relationships, a necessary first step in establishing an

125 effective trapping method for wild beetles. Thus, we investigated how $P$.

126 quercivorus activity varies through phases of the infestation processes on

127 three species of Fagaceae differing in susceptibility: Q. crispula (high

128 susceptibility), Q. serrata (low susceptibility), and Castanea crenata (low

129 susceptibility). 


\section{Materials and methods}

132

133 Study site and tree species

134

135

The study was conducted at Ashiu Forest Research Station in Kyoto,

136 Japan $\left(35^{\circ} 18^{\prime} \mathrm{N}, 135^{\circ} 43^{\prime} \mathrm{E}\right)$, where substantial dieback of $Q$. crispula has

137 been underway since 2002. From July to October 2004, we studied

138 infestation patterns of $P$. quercivorus on tree specimens $>10 \mathrm{~cm}$ in diameter

$139130 \mathrm{~cm}$ above ground (DBH). Twenty-two Q. crispula, eight Q. serrata, and

140 seven $C$. crenata trees were selected for study within a $25 \times 25$-m plot

141 established on a south-facing slope of a secondary forest, at an altitude of

142 approximately $500 \mathrm{~m}$. The forest was dominated by $Q$. crispula, Carpinus

143 laxiflora, and Acer sieboldianum. DBH, perimeter at $50 \mathrm{~cm}$ above the

144 ground, and perimeter at ground height were measured for each tree at the

145 beginning of the study. Setting the southwestern point of the plot as the

146 origin, we also measured the coordinate position of each tree in

147 two-dimensional space. 
149 Beetle activity in the infestation process

150

151

Numbers of $P$. quercivorus that flew to the trees were determined using

152 sticky paper traps (Kobayashi and Hagita 2000; Ueda and Kobayashi 2001b).

153 Two strips of sticky paper (Kamikiri-hoihoi; Earth Biochemical Co., Ltd.,

154 Tokushima, Japan), each $4 \times 50 \mathrm{~cm}$, were attached longitudinally to the

155 upper and lower sides of each tree trunk up to $50 \mathrm{~cm}$ above the ground. We

156 enumerated male (NFM) and female (NFF) beetles that flew to the bark of

157 each tree (per $400 \mathrm{~cm}^{2}$, i.e., total area of sticky paper attached to each tree)

158 by weekly counts of beetles caught in traps.

159 At the same time, we counted the number of holes (NH) bored by $P$.

160 quercivorus on the surface of a trunk (excluding areas covered by traps) up

161 to a height of $50 \mathrm{~cm}$ above the ground. Double counting of holes was

162 prevented by marking previously counted holes with colored push-pins. The

163 surface area over which beetle holes were counted was calculated by

164 assuming the shape of the subject surface was trapezoidal.

Within natural forests, intense $P$. quercivorus flight activity occurs

166 close to the ground (up to $2.5 \mathrm{~m}$ above soil level) (Igeta et al. 2004), and

167 beetle attacks are concentrated on basal parts of trees (Hijii et al. 1991).

168 Because it was difficult to count all beetles that flew to a tree and all holes 
169 that they bored, we restricted monitoring of NFM, NFF, and NH to the area

170 up to $50 \mathrm{~cm}$ above ground.

171 On 29 May 2005, we examined subject trees and classified those with

172 no leaf flush as dead.

173

174 Model selections

175

To discern differences in beetle activity parameters (BAPs) among tree

177 species, we used generalized additive models (GAM) and generalized

178 additive mixed models (GAMM). The best models for predicting BAPs were

179 selected using R 2.11.1 (R Development Core Team 2010). Generally, BAPs

180 fluctuate with time following a unimodal trajectory (Urano 2000; Ueda and

181 Kobayashi 2001b). Thus, we built the nonlinear effect of time into the

182 models predicting BAPs. Linear effects of tree size were also incorporated

183 because BAPs increase with increasing tree size (Akaishi et al. 2006;

184 Yamasaki and Futai 2008). Moreover, we must consider the effect of beetle

185 aggregation caused by the pheromone. This beetle uses an aggregation

186 pheromone to attract conspecifics (Ueda and Kobayashi 2001a; Tokoro et al.

187 2007), and the consequent mass attack by the beetle may conceal primary

188 differences in BAPs among tree species. For instance, BAPs of trees that 
received mass attacks may be significantly higher than those of lightly

attacked trees irrespective of tree species, and low DBH trees with low

191 beetle infection probabilities may have high BAP values when adjacent high

192 DBH trees receive mass attacks. Thus, we regarded the effects of spatial

193 heterogeneity in mass attack, and built them into the model. Taking the

194 effects of these covariates into consideration, we determined whether the

195 "tree species" factor was included in the best models as an explanatory

196 variable for predicting BAPs.

To detect differences among tree species in BAPs in phases 1 and 3,

NFM and NFF were fitted by GAMMs with log link function under the

assumption that these data follow a negative binomial distribution. The

200 candidate explanatory variables were the number of weeks after the first

201 male beetles flew (WEEK), DBH, 2D smoothing effects of location

202 (coordinates of each tree, 2D), and tree species (SP). We assumed a

203 nonlinear effect for WEEK and 2D and a linear effect for DBH and SP. The

204 models were offset by the natural log of the subject surface area of sticky

205 paper $\left(400 \mathrm{~cm}^{2}\right)$. Individual trees were incorporated into the models as a

206 random intercept. The least significant term was removed from the models,

207 and we refitted the models until all terms were significant.

208 To detect differences in BAPs in phase 2, we analyzed the proportion of 209 male beetles that bored holes out of those that flew to the tree (PBM) using 
210 the data with NFM > zero. PBM was calculated from the number of holes

211 newly bored by male beetles per subject bark surface area of each tree

$212\left(\mathrm{AREA}, \mathrm{cm}^{2}\right)$ and the assumed number of flying male beetles per AREA.

213 The latter was calculated by dividing NFM by the subject surface area of

214 sticky paper $\left(400 \mathrm{~cm}^{2}\right)$ and then multiplying it by AREA. PBM was fitted by

215 a GAM with logit link function under the assumption that these data follow a

216 binomial distribution. To deal with the overdispersion of the model, we

217 corrected the standard errors of coefficients by multiplying them by the

218 dispersion parameter. The candidate explanatory variables were WEEK,

219 DBH, and SP. We assumed a nonlinear effect for WEEK and linear effects

220 for DBH and SP. As in the case of the models for NFM and NFF, the least

221 significant term was removed from the model, and we refitted the model

222 until all terms were significant.

\section{Results}

The DBHs of the 37 observed fagaceous trees ranged from 10.4 to 22.2

$227 \mathrm{~cm}$ for $Q$. crispula, 11.9 to $32.2 \mathrm{~cm}$ for $Q$. serrata, and 16.2 to $25.0 \mathrm{~cm}$ for $C$.

228 crenata. Male beetles were trapped on 31 of these observed trees (Table 1).

229 We found holes bored by beetles and we trapped female beetles on 22 of 
230 these 31 trees (Table 1). By the end of the study period, five $Q$. crispula trees and one $C$. crenata tree had died (Table 1). Calculating tree mortality as the 232 proportion of dead to infected trees, mortalities of Q. crispula, Q. serrata, 233 and C. crenata were $38.5 \%(5 / 13), 0 \%(0 / 3)$, and $16.7 \%(1 / 6)$, respectively. The host visitation period of $P$. quercivorus for each tree species is 235 shown in Fig. 1. The first visitation of $P$. quercivorus was observed from 236 July to October on Q. crispula and from July to August on Q. serrata (Fig. 1). 237 In the case of $C$. crenata, the first beetle visitation was observed in July on 238 all trees (Fig. 1). Beetle visitation lasted 1-10 weeks on Q. crispula, 1-11 239 weeks on Q. serrata, and 1-12 weeks on C. crenata (Fig. 1). Among the six 240 dead trees, two Q. crispula and one C. crenata were visited by $P$.

241 quercivorus from July, and the remaining three $Q$. crispula were visited by $P$. 242 quercivorus from August (Fig. 1).

The total numbers of NFM and NFF per unit area $\left(100 \mathrm{~cm}^{2}\right)$ over the 244 research period are shown in Fig. 2a, b. Generally, the numbers of flying 245 beetles were high on the six dead trees and the trees surrounding them (Fig. $2462 \mathrm{a}, \mathrm{b})$.

248 included the effects of 2D, WEEK, and DBH. The 2D smoothing effects on

249 NFM and NFF are shown in Fig. 2c, d, respectively. Zonations of high 
values were observed in predicted values of NFM and NFF (Fig. 2c, d), and these areas correspond to the locations of six dead trees (Fig. 2a, b). The

252 estimated degrees of freedom of smoothing term 2D was $21.76(p<0.001)$

253 for NFM and $19.93(p<0.001)$ for NFF. Figure $2 \mathrm{e}, \mathrm{f}$ shows the effects of 254 WEEK and DBH on NFM and NFF, respectively. Predicted NFM and NFF 255 increased with increasing WEEK, peaked at WEEK values of 2 or 3, and 256 then decreased with further increases in WEEK (Fig. 2e, f). The estimated 257 degrees of freedom of smoothing term WEEK was $4.02(p<0.001)$ for NFM 258 and $5.78(p<0.001)$ for NFF. As shown in previous studies (Kobayashi and 259 Hagita 2000), the peak of NFF was observed a little later than the peak of NFM. We assumed linear effects of DBH on NFM and NFF, and the fitted models demonstrated significant positive effects of $\mathrm{DBH}$ on these variables

262 (Fig. 2e, f; the estimated coefficients were 0.31 for NFM and 0.31 for NFF, $p$ $263<0.001$ for each estimate). With regard to PBM, the best model $(n=137)$ included the effects of WEEK, DBH, and SP. Predicted PBM increased with increasing WEEK, peaked at $\mathrm{WEEK}=4$, and then remained stable until WEEK $=10$ (Fig. 3). The estimated degrees of freedom of smoothing term WEEK was 3.89 ( $p=$ 0.004). The effects of DBH on PBM were positive (the estimated coefficient was 0.11, $p=0.005)$; PBM increased with increasing DBH (Fig. 3). When

270 the coefficient for $Q$. crispula was set to zero, the coefficients estimated for 
Q. serrata $(-1.38, p=0.002)$ and $C$. crenata $(-1.60, p<0.001)$ were both

272 significantly lower than zero, showing significantly lower PBM on $Q$.

273 serrata and C. crerana than that on Q. crispula (Fig. 3).

\section{Discussion}

276

We monitored the infestation patterns of $P$. quercivorus on $22 Q$.

278 crispula, eight $Q$. serrata, and seven $C$. crenata trees in a secondary forest.

279 The mortality rate of selected $Q$. crispula individuals (38.5\%, Table 1$)$ was

280 higher than that of $C$. crenata $(16.7 \%$, Table 1) and Q. serrata $(0 \%$; Table 1$)$.

281 This rank order of susceptibility has been reported previously (Shiomi and

282 Osaki 1997; Inoue et al. 2000; Kobayashi and Hagita 2000; Kobayashi and 283 Shibata 2001; Kobayashi and Ueda 2001; Kamata et al. 2002). Where tree 284 species of different degrees of susceptibility coexist, inappropriate host 285 selection by $P$. quercivorus may result in poor reproduction and, hence, 286 reduced fitness. Thus, we postulated that $P$. quercivorus has a reduced 287 preference for fagaceous trees with low susceptibility. We tested $P$. 288 quercivorus preferences by measuring BAPs on different host tree species.

289 The results of model selections predicting these measures of activity partly 290 supported our postulate. 
study conducted in a natural mixed forest dominated by Cryptomeria

293 japonica suggested that $P$. quercivorus first flies to clusters of $Q$. crispula,

294 not to individual trees (Yamasaki and Sakimoto 2009). This implies that

295 investigations of beetle activity should take into account the effects of

296 neighboring trees. For example, in a phase of mass attack by $P$. quercivorus,

297 trees adjacent to target trees may be severely affected irrespective of their

298 suitability as hosts for the beetle. Moreover, mass attack itself may conceal

299 primary differences in the beetle's preference among tree species. Thus, we used GAMMs in which geographical locations of trees were fitted using splines as trend surfaces, and the patterns of spatial heterogeneity in NFM and NFF (Fig. 2a, b) were well reproduced by the predicted surfaces of the 303 models (Fig. 2c, d). fluctuate with time. The values predicted by GAMMs indicated changes in NFM and NFF with time (Fig. 2e, f), and the unimodal patterns of changes were in accord with previous studies (Urano 2000; Ueda and Kobayashi 308 2001b). 
313 the initiation time of visitation by $P$. quercivorus. Because the numbers of

314 flying beetles in a forest fluctuate with time, differences in the initiation time

315 of beetle visitation among tree species may cause differences in the numbers 316 of flying beetles. In this study, however, there were no clear differences in 317 the initiation time of beetle visitation among the three tree species (Fig. 1). Consequently, the best models for predicting NFM and NFF included 319 the effects of location, time, and tree size. Further inclusion of the effect of 320 tree species did not improve the fitness of the model, which suggested that 321 beetles' flying activity did not differ among host tree species. Thus, the hypothesis that $P$. quercivorus discriminates among host tree species in 323 phases 1 and 3 when flying to trees was rejected. PBM was analyzed to detect differences among host tree species in 325 beetle activity during phase 2 , and the results supported our hypothesis. In 326 addition to temporal fluctuations in beetle activity and the effect of tree size, 327 the effect of tree species was detected; the proportions of male beetles that 328 bored holes out of those that had flown to trees were lower for Q. serrata and C. crenata than for $Q$. crispula (Fig. 3). The same tendency has been

330 reported for $Q$. salicina, which has lower susceptibility to $P$. quercivorus 331 infestation (Yamasaki et al. 2007). 
334 prefer $Q$. crispula to Q. serrata and C. crenata, and selection is made before

335 boring holes in trees. Discrimination of unsuitable trees within the same

336 species has been demonstrated previously; $P$. quercivorus distinguishes

337 suitable $Q$. crispula trees from unsuitable $Q$. crispula at early stages of

338 infestation (Yamasaki and Futai 2008). Differences in beetle activity both

339 among and within tree species suggest that selective forces have acted on $P$.

340 quercivorus during its long co-evolution with the host species, and these

341 forces have led to beetle avoidance of unfavorable host trees. Some

342 proximate factor, for example, a volatile emission from trees, must have

343 been used by $P$. quercivorus to discriminate suitable from unsuitable host

344 tree species. Identification of this factor awaits further studies, which will

345 contribute to the protection of forests dominated by fagaceous trees, the 346 hosts of $P$. quercivorus.

\section{Acknowledgments}

We are indebted to all staff members of Ashiu Forest Research Station,

351 Field Science Education and Research Center, Kyoto University, for 
352 enabling us to conduct the research. We thank Dr. D. Fujiki, Mr. A. Iwatake, 353 Mr. Y. Takeuchi, Mr. Y. Ito, and Mr. and Mrs. Harada for their assistance in 354 the fieldwork. We also thank all members of the Laboratory of Forest 355 Biology, Kyoto University, for their help and advice during the work. This 356 study was supported by Grants-in-Aid for Scientific Research from the 357 Ministry of Education, Culture, Sports, Science and Technology (no. 358 15380106) and the 21st Century COE Program of Kyoto University 359 "Innovative Food and Environmental Studies Pioneered by Entomomimetic 360 Sciences" from the Japan Society for the Promotion of Science. 


\section{References}

Akaishi D, Kamata N, Nakamura K (2006) Initial stage of an infestation of Platypus quercivorus (Coleoptera: Platypodidae) in a secondary forest dominated by Quercus serrata and Quercus variabilis (in Japanese with English summary). J Jpn For Soc 88:274-278

Byers JA, Zhang Q-H, Birgersson G (2004) Avoidance of nonhost plants by a bark beetle, Pityogenes bidentatus, in a forest of odors. Naturwissenschaften 91:215-219

Campbell SA, Borden JH (2006) Integration of visual and olfactory cues of hosts and non-hosts by three bark beetles (Coleoptera: Scolytidae). Ecol Entomol 31:437-449

Esaki K, Kato K, Kamata N (2004) Stand-level distribution and movement of Platypus quercivorus adults and patterns of incidence of new infestation. Agric For Entomol 6:71-82

Hijii N, Kajimura H, Urano T, Kinuura H, Itami H (1991) The mass mortality of oak trees induced by Platypus quercivorus (Murayama) and Platypus calamus Blandford (Coleoptera: Platypodidae): the density and spatial distribution of attack by the beetles. J Jpn For Soc 73:471-476

383 Igeta Y, Esaki K, Kato K, Kamata N (2004) Spatial distribution of a flying 
ambrosia beetle Platypus quercivorus (Coleoptera: Platypodidae) at the stand level. Appl Entmol Zool 39:583-589

386

387

388

389

390

391

392

393

394

395

396

397

398

399

400

401

402

403

404

Inoue M, Nishigaki S, Nishi N (2000) Attack by the oak borer, Platypus quercivorus, to living oak trees (in Japanese with English summary). Appl For Sci 9(1):127-131

Ito S, Yamada T (1998) Distribution and spread of the mass mortality of oak trees (in Japanese). J Jpn For Soc 80:229-232

Kamata N, Esaki K, Kato K, Igeta Y, Wada N (2002) Potential impact of global warming on deciduous oak dieback caused by ambrosia fungus Raffaelea sp. carried by ambrosia beetle Platypus quercivorus (Coleoptera: Platypodidae) in Japan. Bull Entomol Res 92:119-126

Kamata N, Esaki K, Mori K, Takemoto H, Mitsunaga T, Honda H (2008) Field trap test for bioassay of synthetic (1S,4R)-4-isopropyl-1-methyl-2-cyclohexen-1-ol as an aggregation pheromone of Platypus quercivorus (Coleoptera : Platipodidae). J For Res 13:122-126

Kashiwagi T, Nakashima T, Tebayashi S, Kim CS (2006) Determination of the absolute configuration of quercivorol, $(1 S, 4 R)-p$-menth-2-en-1-ol, an aggregation pheromone of the ambrosia beetle Platypus quercivorus (Coleoptera: Platypodidae). Biosci Biotech Bioch $70: 2544-2546$ 
405

406

407

408

409

410

411

412

413

414

415

416

417

418

419

420

421

422

423

424

425

Kato K, Esaki K, Igeta Y, Kamata N (2001) Comparison of reproductive success of Platypus quercivorus among four species of the family Fagaceae (preliminary report) (in Japanese). Chubu For Res 49:81-84

Kobayashi M, Hagita M (2000) Process of mass mortality of oak trees and capture of Platypus quercivorus Murayama (Coleoptera:

Platypodidae) (in Japanese with English summary). Appl For Sci 9(1):133-140

Kobayashi M, Nozaki A, Kinuura H (2004) Influence of sap on reproduction of Platypus quercivorus (Murayama) (Coleoptera: Platypodidae) (in Japanese). Appl For Sci 13:155-159

Kobayashi M, Shibata S (2001) Infestation of Platypus quercivorus (Murayama) (Coleoptera: Platypodidae) at a newly damaged forest by the beetle (I): Investigation in Maizuru, Kyoto Prefecture (in Japanese with English summary). Appl For Sci 10(2):73-78

Kobayashi M, Ueda A (2001) Infestation of Platypus quercivorus (Murayama) (Coleoptera: Platypodidae) at newly damaged forests by the beetle (II): Investigation in Wachi and Keihoku, Kyoto Prefecture (in Japanese with English summary). Appl For Sci 10(2):79-84

Kobayashi M, Ueda A (2005) Wilt disease of Fagaceae trees caused by Platypus quercivorus (Murayama) (Coleoptera: Platypodidae) and the associated fungus: Aim is to clarify the damage factor (in Japanese 
Paine TD, Raffa KF, Harrington TC (1997) Interactions among scolytid bark beetles, their associated fungi, and live host conifers. Annu Rev Entomol 42:179-206

430 discrimination in three species of Dendroctonus (Coleoptera: Scolytidae). Agric For Entomol 7:219-230

R Development Core Team (2010) R: A language and environment for statistical computing. In. R Foundation for Statistical Computing, Vienna, Austria

Shiomi S, Osaki S (1997) Mass mortality of Quercus serrata and $Q$. mongolica in Hyogo Prefecture (in Japanese). Appl For Sci 6:197-198

Soné K, Mori T, Ide M (1998) Life history of the oak borer, Platypus quercivorus (Murayama) (Coleoptera: Platypodidae). Appl Entmol Zool 33:67-75

Tokoro M, Kobayashi M, Saito S, Kinuura H, Nakashima T, Shoda-Kagaya E, Kashiwagi T, Tebayashi S, Kim CS, Mori K (2007) Novel aggregation pheromone, $(1 S, 4 R)$-p-menth-2-en-1-ol, of the ambrosia beetle, Platypus quercivorus (Coleoptera: Platypodidae). Bull For For Prod Res Inst 6:49-57

Ueda A, Kobayashi M (2001a) Aggregation of Platypus quercivorus 
(Murayama) (Coleoptera: Platypodidae) on oak logs bored by males of the species. J For Res 6:173-179

449 Ueda A, Kobayashi M (2001b) Seasonal change of number of Platypus quercivorus (Murayama) and P. calamus Blandford (Coleoptera: summary). J Jpn For Soc 83:77-83

Urano T (2000) Relationships between mass mortality of two oak species (Quercus mongolica Turcz. var. grosseserrata Rehd. et Wils. and $Q$. serrata Thunb.) and infestation by and reproduction of Platypus quercivorus (Murayama) (Coleopetra: Platypodidae). J For Res 5:187-193

Wood DL (1982) The role of pheromones, kairomones, and allomones in the host selection and colonization behavior of bark beetles. Annu Rev Entomol 27:411-446

Yamasaki M, Futai K (2008) Host selection by Platypus quercivorus (Murayama) (Coleoptera: Platypodidae) before and after flying to trees. Appl Entmol Zool 43:249-257

Yamasaki M, Iwatake A, Futai K (2007) A low Platypus quercivorus hole density does not necessarily indicate a small flying population. J For Res 12:384-387

467 Yamasaki M, Sakimoto M (2009) Predicting oak tree mortality caused by the 
ambrosia beetle Platypus quercivorus in a cool-temperate forest. $\mathrm{J}$

469 Appl Entmol 133:673-681

470 Zhang Q-H (2003) Interruption of aggregation pheromone in Ips

471 typographus (L.) (Col. Scolytidae) by non-host bark volatiles. Agric

472 For Entomol 5:145-153

473 Zhang Q-H, Schlyter F (2004) Olfactory recognition and behavioural avoidance of angiosperm nonhost volatiles by conifer-inhabiting bark

475 beetles. Agric For Entomol 6:1-19

476

477

478 
479 Table 1. Numbers of trees observed, trees on which male Platypus

480 quercivorus were trapped, trees on which beetle holes were observed, trees

481 on which female beetles were trapped, and dead trees.

482

\begin{tabular}{lccccc}
\hline & $\begin{array}{c}\text { Observed } \\
\text { trees }\end{array}$ & $\begin{array}{c}\text { With male } \\
\text { beetles }\end{array}$ & $\begin{array}{c}\text { With beetle } \\
\text { holes }\end{array}$ & $\begin{array}{c}\text { With female } \\
\text { beetles }\end{array}$ & Dead \\
\hline Q. crispula & 22 & 18 & 13 & 13 & 5 \\
Q. serrata & 8 & 6 & 3 & 3 & 0 \\
C. crenata & 7 & 7 & 6 & 6 & 1 \\
\hline
\end{tabular}

483

484 Data are for Quercus crispula, Q. serrata, and Castanea crenata. 


\section{Figure legends}

486

487 Fig. 1. Host visitation period of Platypus quercivorus for 18 Quercus

crispula, 6 Q. serrata, and 7 Castanea crenata individuals. Circles

489 connected by a solid line show the first and last days of beetle visitation.

490 Gray circles and lines show data for surviving trees. Black circles and lines

491 show data for dead trees.

492

493 Fig. 2. Numbers of flying male (a) and female (b) beetles per $100 \mathrm{~cm}^{2}$ of

494 bark surface (NFM and NFF) for 37 subject trees over the research period.

495 The location of each tree is plotted in two-dimensional space. Black and grey

496 bars show data for dead and surviving trees, respectively.

497 NFM (c) and NFF (d) at each location predicted by generalized additive 498 mixed models. Predictions were made by assuming that the number of weeks 499 after the first male beetle's flying (WEEK) was 2 and the diameter of trees at 500 breast height (DBH) was $20 \mathrm{~cm}$. NFM (e) and NFF (f) predicted for the 501 combination of various values of WEEK and DBH by generalized additive 502 mixed models. Predictions were made by assuming that the tree was located 503 at the center of the $25 \times 25-\mathrm{m}$ study plot (coordinates of the location $\mathrm{x}=12.5$ $504 \mathrm{~m}$ and $\mathrm{y}=12.5 \mathrm{~m})$. 
505

506 Fig. 3. The proportion of male beetles that bored holes out of those that flew 507 to the tree (PBM), predicted by a generalized additive model. Values are 508 predicted for combinations of various values of the number of weeks after 509 the first male beetle's flying (WEEK) and diameter of trees at breast height 510 (DBH). Predicted values are shown separately for the three studied tree

511 species: Quercus crispula (left), Q. serrata (center), and Castanea crenata 512 (right). 
Fi g. 1

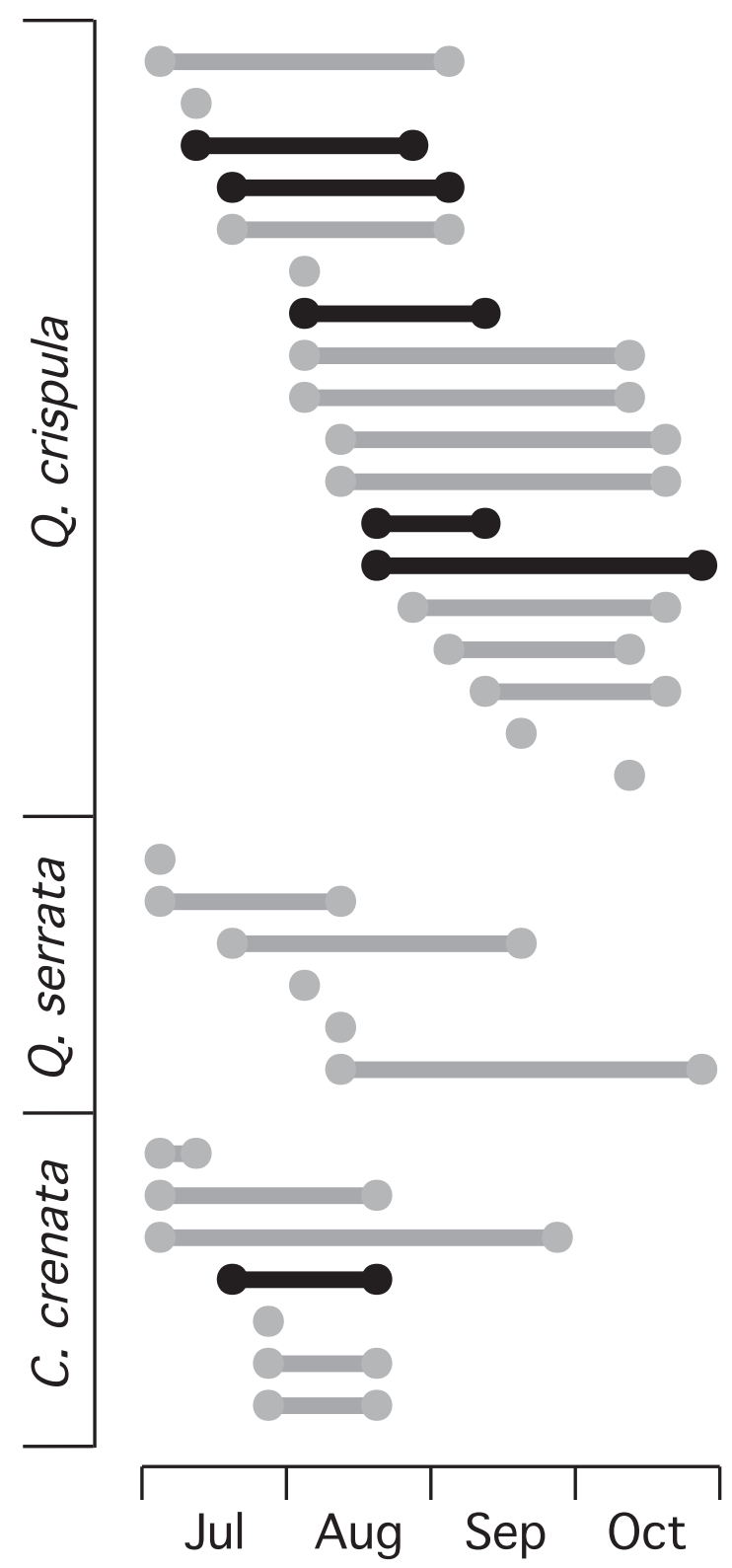


Fi g. 2
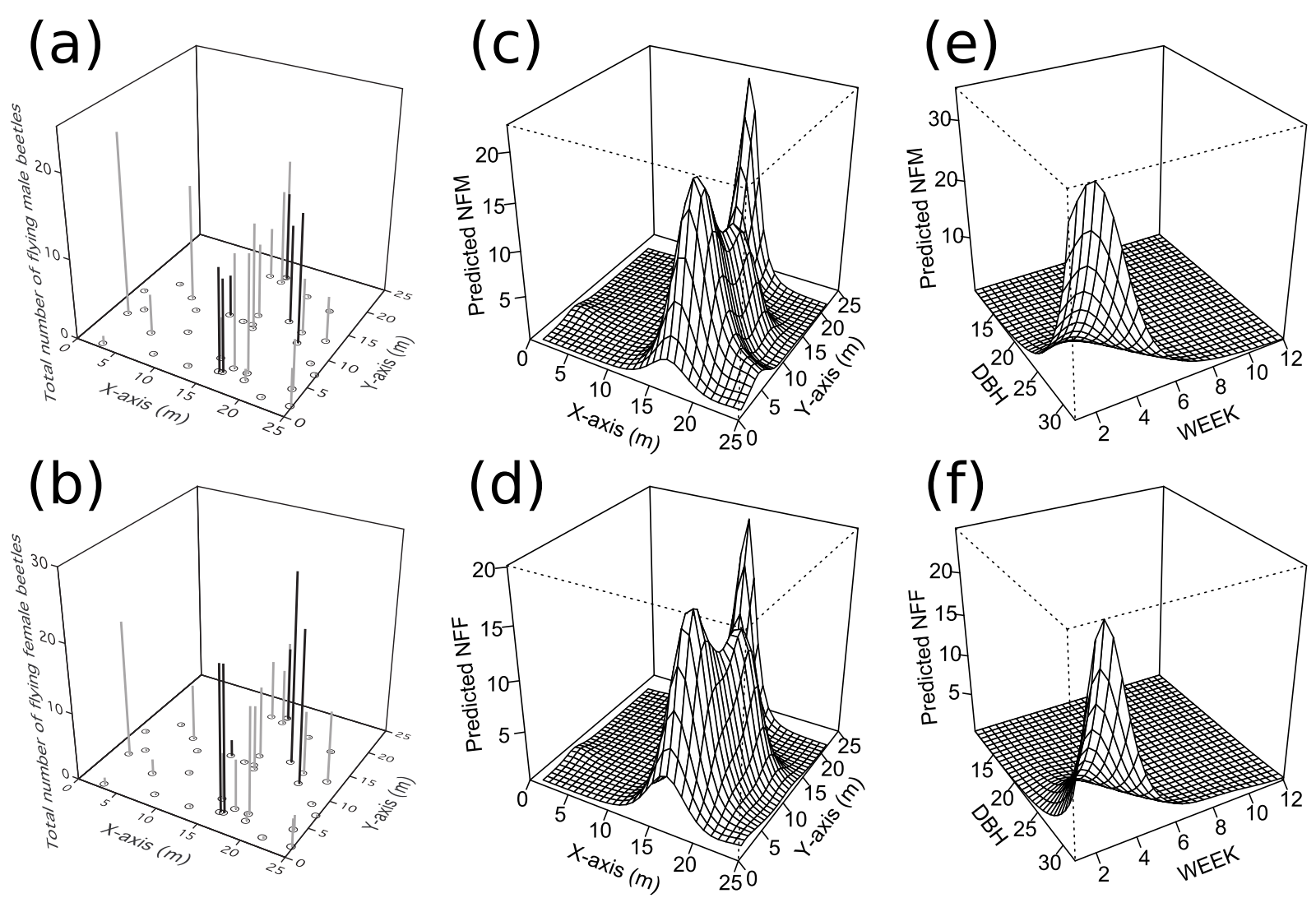
